\title{
Short-Term Effect of COX-2 Selective Inhibitor as an Adjunct for the Treatment of Periodontal Disease - A Clinical Double-Blind Study in Humans
}

\author{
Márcia de Noronha PINHO \\ Leonardo Bíscaro PEREIRA \\ Sérgio Luís Scombatti de SOUZA \\ Daniela Bazan PALIOTO \\ Márcio Fernando de Moraes GRISI \\ Arthur Belém NOVAES JR. \\ Mario TABA JR.
}

Department of Oral and Maxillofacial Surgery and Traumatology and Periodontology, Dental School of Ribeirão Preto, University of São Paulo, Ribeirão Preto, SP, Brazil

\begin{abstract}
Adjunctive therapeutic strategies that modulate the inflammatory mediators can play a significant role in periodontal therapy. In this double-blind, placebo-controlled study, 60 subjects diagnosed as periodontitis patients were evaluated for 28 days after periodontal treatment combined with selective cyclooxygenase-2 (COX-2) inhibitor. The experimental group received scaling and root planning (SRP) combined with the Loxoprofen antiinflammatory drug (SRP+Loxoprofen). The control group received SRP combined with placebo (SRP+placebo). Plaque index (PI), probing pocket depth (PD) and bleeding on probing (BOP) were monitored with an electronic probe at baseline and after 14 and 28 days. Both groups displayed clinical improvement in PD, PI and BOP. They also showed statistically similar values $(\mathrm{p}>0.05)$ of PD reduction on day $14(0.4 \mathrm{~mm})$ and on day $28(0.6 \mathrm{~mm})$. At the baseline, few deeper sites $(\geq 7 \mathrm{~mm})$ from SRP+Loxoprofen group were responsible and most PD reduction was observed after 14 days $(\mathrm{p}<0.05)$. The percentage of remaining deep pockets $(\geq 7 \mathrm{~mm})$ after 14 days in the SRP+Loxoprofen group was significantly lower $(p<0.05)$ than in the SRP+placebo group. Loxoprofen presents potential effect as an adjunct of periodontal disease treatment, but long-term clinical trials are necessary to confirm its efficacy.
\end{abstract}

Key Words: periodontitis therapy, prostaglandin, adjunctive therapy, inflammation.

\section{INTRODUCTION}

Periodontal disease is a high prevalent infectious injury caused by specific bacterial species. However, most of the tissue breakdown is indirectly caused by toxic bacterial products that trigger the host response. Hostderived enzymes known as matrix metalloproteinases (MMPs), changes in osteoclast activity by cytokines and other inflammatory mediators like prostanoids are responsible for most periodontal tissue destruction (1). The cyclooxygenase (COX) products of the arachidonic acid or simply prostanoids (PGs) and tromboxane $\left(\mathrm{TxB}_{2}\right)$ are produced by activated monocytes, platelets and fibroblasts. Both PGs and $\mathrm{TxB}_{2}$ are strong vasoactive mediators and stimulators of bone resorption (1-3).

Several host modulatory agents have been investigated in clinical trials. Non-steroidal antiinflammatory drugs (NSAIDs), sub-antimicrobial dose of doxycycline and bisphosphonates or combination of drugs have been successfully used as an adjunct to non-surgical mechanical periodontal therapy. The results of host modulation studies have shown that this approach may be a potential target to reduce tissue destruction. NSAIDs blockade the pro-inflammatory cytokines; sub-dose of doxycycline blockades the metalloproteinases and the bisphosphonates blockade the osteoclast activity $(4,5)$. 
The basis of antiinflammatory drugs in periodontal disease treatment is related to the control of prostaglandin $\mathrm{E}_{2} \quad\left(\mathrm{PGE}_{2}\right)$ through the inhibition of cyclooxygenase-2 (COX-2) enzyme. Higher levels of $\mathrm{PGE}_{2}$ are associated with increased gingival inflammation and alveolar bone loss $(1,3,6,7)$. Therefore, the purpose of this study was to evaluate a selective COX2 inhibitor derived from phenylpropionic acid, Loxoprofen sodium, as an adjunct for periodontal disease treatment, using probing pocket depth (PD) to verify the inflammation reduction.

\section{MATERIAL AND METHODS}

\section{Sample Distribution and Study Design}

This was a randomized, double-blind, placebocontrolled study, which used parallel inter-subjects and a split-mouth design. Sixty healthy non-smoking subjects with at least 20 teeth, ranging in age from 35-50 years, who had two or more teeth with clinical attachment loss (CAL) $\geq 6 \mathrm{~mm}$ and one or more sites with PD $\geq 5 \mathrm{~mm}$ were selected according to the established periodontitis criteria. Exclusion criteria were: presence of systemic diseases, pregnancy or nursing women, gastric ulcer, hypersensitivity to antiinflammatory drugs, use of antibiotic, corticoids, immunosuppressive drugs or any NSAIDs within the past three months.

The 60 patients were randomly assigned to experimental and control groups. The experimental group received periodontal treatment that consisted of conventional scaling and root planning (SRP), using ultrasonic scaler (Bob-Cat, Dentsply/Cavitron, Long Island City, NY, USA) and Gracey curettes (Hu-Friedy, Chicago, IL, USA) combined with $60 \mathrm{mg}$ /day of Loxoprofen (Loxonin; Sankyo Pharma Brasil Ltda, Barueri, SP, Brazil) during 28 days (SRP+Loxoprofen). The control group received the same SRP treatment combined with placebo (SRP+Placebo). Periodontal treatment was performed in 2 phases by a blinded experienced periodontist (BP). Randomly, half-mouth received one-session of SRP at the baseline and the contra-lateral side of the mouth received one-session of SRP on day 14 (Fig. 1).

\section{Clinical Procedures, Measurements and Monitoring}

At baseline, medical and dental histories were recorded and the following clinical parameters were measured: PD measured at 6 sites/teeth using an electronic probe (Florida Probe Corporation, Gainesville, Fl, USA); the percentage of sites with bleeding on probing (BOP) and the percentage of tooth surfaces with dental plaque (PI) (Table 1). The patients received mechanical therapy (SRP), oral hygiene instruction and orientation about medication. Coded medication or placebo packages were supplied for the first 14 days. Then, at the second appointment, clinical measurements were recorded and drug use was assessed by means of medication package inspection and pills counting. Also, oral hygiene instruction was reinforced and the contralateral side of the mouth received SRP. Mechanical therapy was completed and the remaining medication or placebo packages were supplied for the next 14 days. At the end of 28 days, all clinical measurements were retaken by the same blinded operator and medication use was reviewed.

\section{Statistical Analysis}

The clinical measurements per patient were assessed. The mean and standard deviations were calculated and non-parametric analyses were performed using statistical software (Statistica for Window; StatSoft, Inc., Tulsa, OK, USA). The number of sites

\begin{tabular}{|c|c|c|}
\hline SRP (session 1) & SRP (session 2) & SRP (session 3) \\
\hline PD & PD & PD \\
\hline BOP & BOP & BOP \\
\hline PI & PI & PI \\
\hline Baseline & 14 days & 28 days \\
\hline
\end{tabular}

Figure 1. Study design and timeline. All 60 patients had their clinical measurements recorded at baseline, 14 and 28 days. Scaling and root planning was performed in 2 sessions, halfmouth at the baseline and the remaining contra-lateral teeth after 14 days. Two groups were determined based on the Loxoprofen or placebo intake as an adjunct to the non-surgical periodontal therapy. Loxoprofen dosage was $60 \mathrm{mg}$ /day during 28 days. Placebo pills were identical to the real medication to keep the patients and operator blinded. Probing pocket depth (PD), Bleeding on probing (BP) and Plaque index (PI). 
with initial $\mathrm{PD}<4 \mathrm{~mm}, 4<7 \mathrm{~mm}$ and $7 \mathrm{~mm}$ per patient were computed for further analysis. Mann-Whitney test was used to compare the differences between groups (SRP+Loxoprofen and SRP+Placebo). Friedman test compared differences among the time points (baseline, 14 and 28 days) in each group. Chi-square test was used for nominal variables. All statistical analysis considered the significant level of $5 \%$. The Cohen's $d$ effect size was also calculated for further interpretation of the observed statistical significance.

\section{RESULTS}

All 60 patients completed the study, presenting $100 \%$ of medication compliance or placebo, and no complain of adverse reactions to the Loxoprofen therapy. Compliance was monitored at both recall and final exam visits by the assessment of the amount of medication taken from the original prescription package.

Baseline demographic characteristics of the patients divided by groups are presented in Table 1. There were no statistically significant differences $(p>0.05)$ between groups regarding the evaluated parameters at baseline. The smaller and uniform amount of plaque recorded in both groups after 14 and 28 days suggest

Table 1. Baseline parameters for SRP+Loxoprofen and $\mathrm{SRP}+\mathrm{Placebo}$ groups. No statistically significant differences were observed between groups $(p>0.05)$. Patients received the periodontal treatment according to a random order $(n=60)$. The randomization was assured due to the arbitrary distribution of the coded medication or placebo.

\begin{tabular}{lcc}
\hline Parameters & \multicolumn{2}{c}{ Groups } \\
\cline { 2 - 3 } & SRP+Loxoprofen & SRP+Placebo \\
\hline Age (yrs) & $41 \pm 4$ & $42 \pm 5$ \\
Age range & $35-49$ & $35-50$ \\
Gender (male/female) & $14 / 16$ & $14 / 16$ \\
Race (whites/non-whites) & $21 / 9$ & $18 / 12$ \\
PD (mm) & $2.6 \pm 0.6$ & $2.4 \pm 0.6$ \\
BP (\%) & $23.8 \pm 10.0$ & $23.6 \pm 11.1$ \\
PI (\%) & $61.0 \pm 25.4$ & $68.0 \pm 27.0$ \\
\hline
\end{tabular}

$\mathrm{PD}=$ Probing pocket depth; $\mathrm{BOP}=$ Bleeding on probing; $\mathrm{PI}=$ Plaque index. the high degree of patient compliance with the proposed protocol.

The therapeutic approach used in this study, SRP+Loxoprofen or SRP+Placebo, promoted clinical improvement with statistically significant reduction $(\mathrm{p}<0.05)$ of PD and BOP during the evaluated intervals (between 0-14, 0-28 and 14-28 days). Regarding PI, the reduction was statistically significant $(p<0.05)$ between $0-14$ and 0-28 days, but not between 14-28 days $(\mathrm{p}>0.05)$.

Although both groups showed clinical improvement, there were no statistically significant differences $(p>0.05)$ in PD reduction between groups after 28 days. SRP+Loxoprofen and SRP+Placebo groups showed a PD reduction of $0.4 \mathrm{~mm}$ on day 14. After 28 days, the overall PD reduction for both groups was 0.6 $\mathrm{mm}(\mathrm{p}>0.05)$.

Comparative analyses of the sites that did not receive SRP therapy in the first 14 days showed greater PD reduction than the control sites (no-SRP+placebo). This difference was statistically significant $(p<0.05)$ after 14 days, suggesting the potential effect of the adjunctive therapy, although not clinically relevant. PD reduction mean was $0.3 \pm 1.0 \mathrm{~mm}$ for Loxoprofen therapy solely and $0.2 \pm 1.1 \mathrm{~mm}$ for control sites. On day 14, both groups received SRP at the contra-lateral side of the mouth followed by supplementary dose of medication or placebo for the next 14 days.

Considering the patient as an experimental unit, there was no significant difference $(p>0.05)$ in the PD reduction between patients that used the medication and those that received placebo. The differences were not statistically significant neither after 14 days nor after 28 days of periodontal treatment combined with adjunctive antiinflammatory therapy $(\mathrm{p}>0.05)$. On day 14 , the PD reduction in sites with initial $P D \geq 7 \mathrm{~mm}$, in the SRP+Loxoprofen group, $(2.2 \pm 2.0 \mathrm{~mm})$ was statistically greater than in the SRP+placebo group $(1.5 \pm 1.8 \mathrm{~mm})$ $(\mathrm{p}<0.05)$.

Figure 2 demonstrated that after 14 days, the remaining deep pockets $\geq 7 \mathrm{~mm}$ of the SRP+Loxoprofen group was significantly lower than in the SRP+placebo group $(p<0.05)$. However, the effect size for the PD reduction observed in the study was very low $(d<0.4)$, indicating that the result is not clearly relevant. After 28 days, there were no statistically significant differences $(p>0.05)$ in PD reduction among groups and the percentage of remaining deep pockets were similar. 

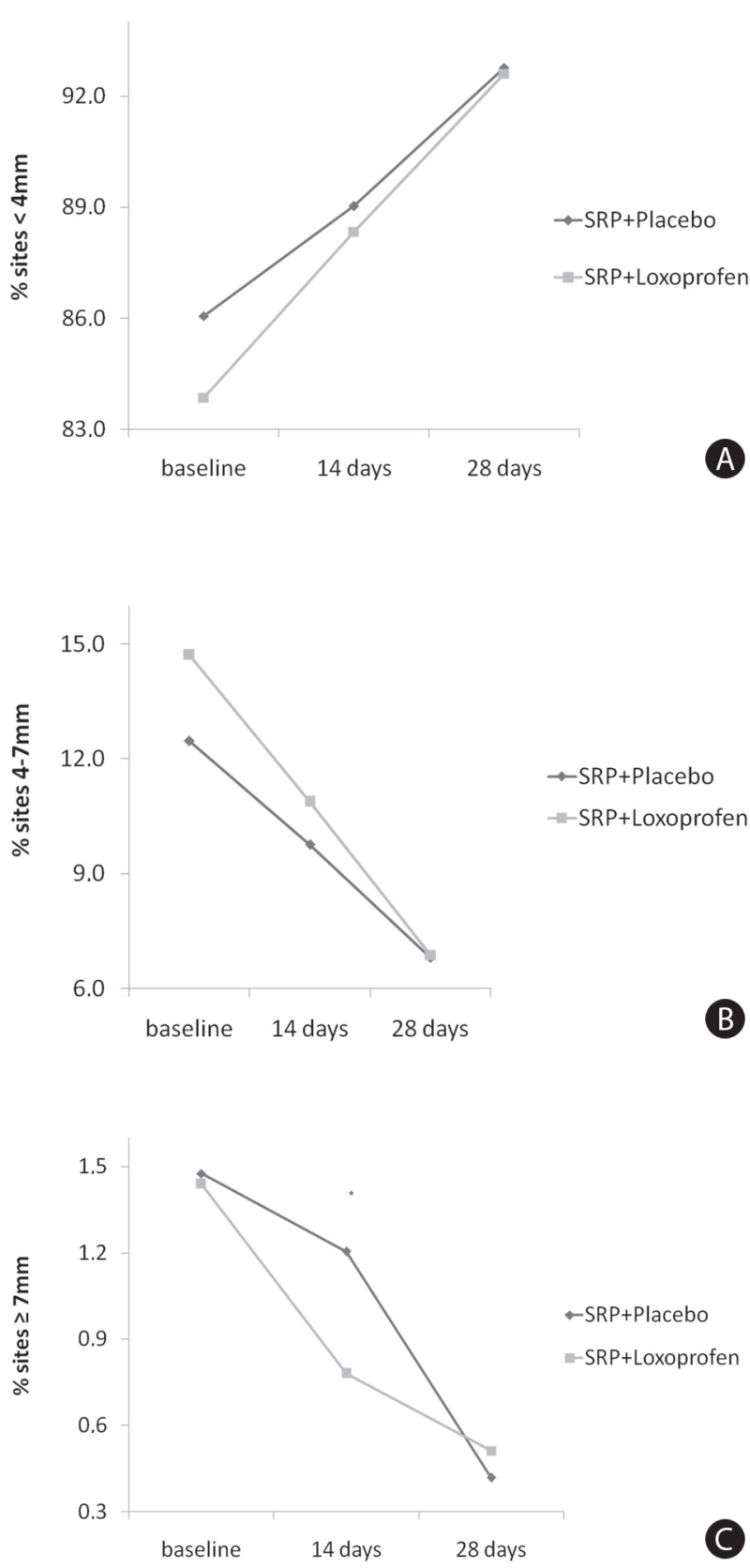

Figure 2. Percentage of sites on the different time-points according to the probing pocket depth (PD). Panel $\mathrm{A}=$ shows the increasing number of shallow periodontal pockets $(<4 \mathrm{~mm})$ over 14 and 28 days. No statistically significant differences $(p>0.05)$ were observed for this PD sites. Panel B = shows that the periodontal pockets $4<7 \mathrm{~mm}$ presented a reduction tendency over time. In Panel C, there is a significant difference $(\mathrm{p}<0.05)$ in the percentage of deep periodontal pocket ( $\geq 7 \mathrm{~mm}$ ) between groups on day 14 . The SRP+Loxoprofen therapy promoted faster reduction in the number of the deep periodontal pockets but no difference was observed after 28 days.

\section{DISCUSSION}

This short-term study evaluated the effect of Loxoprofen on the reduction of probing pocket depth. It was observed a limited suggestive potential for the treatment of deep periodontal pockets. Nevertheless, the initial difference in PD reduction and the benefits on the deeper periodontal pockets were insignificant after 28 days or longer. Likewise, other studies $(2,8,9)$ have found no differences in PD reduction between placebo and NSAID group after 28 days.

When the PD reduction was evaluated considering the initial measurements of PD, the deeper periodontal pockets showed additional improvement in the first 14 days after the SRP+Loxoprofen therapy. Moreover, in the SRP+Loxoprofen group the percentage of remaining periodontal pockets $\geq 7 \mathrm{~mm}$ was significantly reduced after 14 days, indicating some limited but potential effect of the adjunctive therapy on the early stage of periodontal treatment. Significant reduction of $\mathrm{PGF}_{2 \alpha}$ and $\mathrm{PGE}_{2}$ in the gingival tissue levels was observed in the first 10 days after mechanical therapy combined with NSAID adjunctive treatment (2). These findings suggest that the antiinflammatory effect and subsequent PD reduction is more evident in the early phase of the adjunctive therapy (8).

Overall, no significant differences were observed in $\mathrm{PD}$ reduction but in deep periodontal pockets $(\mathrm{PD} \geq 7$ $\mathrm{mm}$ ). This can probably be explained by the fact that localized site measurements produce mean values that do not adequately represent the periodontal disease of the entire mouth. The larger number of healthy sites obscures a few deeper sites, commonly found in chronic periodontitis, since the limited amount of deep pockets might not influence the general result. Multi-level data analysis considering inter-dependent variables are helpful but require advanced resources (10).

In addition, the demonstration of additional benefits of any adjunctive therapy for periodontitis treatment needs adequate study designs. Clinical improvement is usually obtained due to a successful mechanical therapy and thus, only a small effect can be attributed to the adjunctive therapy. The lack of difference in PI reduction between groups, after 14 and 28 days, and the clinical improvement in the control group support the idea that most of the clinical benefits frequently come from conventional therapy associated to an effective plaque control. Therefore, even under medication, some 
degree of inflammation and PD reduction may be related to patient motivation and cooperation (11). The outcomes of the present study are supported by investigations using NSAIDs for experimental gingivitis treatment $(8,12)$.

Regarding NSAID efficacy period, it has been shown that the inhibitory effect of $\mathrm{PGE}_{2}$ continues only during drug intake phase and will end after drug therapy cessation (13). In this short-term evaluation, PD and BOP presented significant improvement during the observation period. However, no differences were detected between groups on day 28 , which indicate that mechanical therapy alone or combined with Loxoprofen can successfully reduce the inflammation and promote pocket depth reduction. Therefore, the extended use of NSAIDs as an adjunctive therapy is not essential to reduce gingival inflammation and should be limited to the active phases of periodontal disease.

The long-term use of NSAIDs has been revisited by US Food and Drug Administration (FDA). FDA reported that the widely use of a high-selective COX-2 inhibitor for more than 18 months induces risk of heart attack and stroke (14). This fact may be explained by the effect of coxibs on the inhibition of endothelial prostacyclin $\left(\mathrm{PGI}_{2}\right)$ synthesis. $\mathrm{PGI}_{2}$ prevents platelet aggregation and causes vasodilatation. These effects contrast with platelet COX-1-derived thromboxane $\mathrm{A}_{2}\left(\mathrm{TxA}_{2}\right)$, which causes platelet aggregation, vasoconstriction and vascular proliferation. Thus, selective COX-2 blockade favors $\mathrm{TxA}_{2}$ and potentially pre-disposes patient to hypertension, heart attack and stroke (15).

One limitation of this study is the lack of biochemical analyses of the gingival crevicular fluid (GCF) and tissue biopsy. Nevertheless, although PGs levels of the patients were not measured in this experiment, it seems like the present findings are related to the mechanism of the COX-2 inhibition and are supported by previous studies $(7-9,12,16)$.

The effects of NSAIDs on $\mathrm{PGE}_{2}$ levels $(2,13)$, gingival inflammation (17) and alveolar bone loss $(16,18,19)$ have been widely examined in human, animal and in vitro experiments $(6,20)$. In general, the results have shown beneficial effect the early phase of periodontal treatment, gingivitis and prevention of bone loss. However, the variety of the results found in the literature can be attributed to differences in the study designs, dosage and duration of NSAID therapy, and the selectivity of NSAID to COX-2 (1).
The NSAID used in this study (Loxoprofen) is more selective to COX-2 than COX-1 and demonstrated a limited advantage when compared to placebo, combined or not to the mechanic therapy. However, the clinical significance may be questioned and the indication of this medicament should be restricted to clinical situations where deep pockets are present. Consequently, the prescription of Loxoprofen as an adjunct for the non-surgical mechanical therapy may have an indication on the early stages of the treatment of advanced forms of periodontal diseases. Further investigations in selected patients may elucidate this potential indication.

The following conclusions can be drawn: 1 . adjunctive antiinflammatory therapy may lead to a faster and greater probing pocket depth reduction than conventional periodontal therapy; 2 . health condition should be carefully evaluated before recommending Loxoprofen as an adjunct for clinical use; 3. Loxoprofen antiinflammatory drug presents potential effect as an adjunct of periodontal disease treatment, but long-term clinical trials are necessary to confirm its efficacy.

\section{RESUMO}

Estratégias terapêuticas adjuvantes que modulam os mediadores inflamatórios podem ter função significante na terapia periodontal. Neste estudo duplo-cego controlado com placebo, 60 indivíduos diagnosticados com periodontite foram avaliados por 28 dias após tratamento periodontal combinado com inibidor seletivo de COX-2. O grupo experimental foi tratado com raspagem e alisamento radicular combinado com medicação antiinflamatória Loxoprofeno (RAR+Loxoprofen). O grupo controle foi tratado com raspagem e alisamento radicular combinado com medicação placebo (Raspagem e alisamento radicular $\mathrm{RAR}+$ placebo). Presença de placa (PI), profundidade de sondagem (PS) e sangramento à sondagem (SS) foram monitoradas com auxílio de uma sonda computadorizada no início do estudo e após 14 e 28 dias. Os dois grupos demonstraram melhora clínica em relação a PS, PI e SS. Também foi observado valores semelhantes ( $p>0,05)$ de redução da PS nos períodos de 14 dias $(0,4 \mathrm{~mm})$ e 28 dias $(0,6 \mathrm{~mm})$. No início do estudo, alguns sítios profundos $(\geq 7$ $\mathrm{mm})$ do grupo RAR+Loxoprofen foram os responsáveis pela maior redução da PS depois de 14 dias $(\mathrm{p}<0,05)$. A porcentagem de bolsas periodontais profundas $\geq 7 \mathrm{~mm}$ após 14 dias no grupo RAR +Loxoprofen foi significativamente inferior do que o grupo $R A R+$ placebo $(p<0.05)$. A medicação Loxoprofen apresenta potencial efeito adjuvante à terapia periodontal, mas estudos de longo prazo são necessários para confirmar sua eficácia.

\section{ACKNOWLEDGMENTS}

Authors thank support from CAPES, FAPESP (grant \# 2001/ 
14066-6) and Sankyo Pharma Ltda., Barueri, SP, Brazil. The "first-last-author-emphasis" norm (FLAE) was used for the authors sequence.

\section{REFERENCES}

1. Noguchi K, Ishikawa I. The roles of cyclooxygenase-2 and prostaglandin E2 in periodontal disease. Periodontol 2000 2007;43:85-101.

2. Vardar S, Baylas H, Huseyinov A. Effects of selective cyclooxygenase-2 inhibition on gingival tissue levels of prostaglandin E2 and prostaglandin F2alpha and clinical parameters of chronic periodontitis. J Periodontol 2003;74:57-63.

3. Reynolds MA, Prudêncio A, Aichelmann-Reidy ME, Woodward K, Uhrich KE. Non-steroidal antiinflammatory drug (NSAID)-derived poly(anhydride-esters) in bone and periodontal regeneration. Curr Drug Deliv 2007;4:233-239.

4. de Queiroz AC, Taba M Jr, O'Connell PA, da Nóbrega PB, Costa PP, Kawata VK et al.. Inflammation markers in healthy and periodontitis patients: a preliminary data screening. Braz Dent J 2008;19:3-8.

5. Kirkwood KL, Cirelli JA, Rogers JE, Giannobile WV. Novel host response therapeutic approaches to treat periodontal diseases. Periodontol 2000 2007;43:294-315.

6. Tipton DA, Flynn JC, Stein SH, Dabbous M. Cyclooxygenase2 inhibitors decrease interleukin-1beta-stimulated prostaglandin E2 and IL-6 production by human gingival fibroblasts. J Periodontol 2003;74:1754-1763.

7. Offenbacher S, Williams RC, Jeffcoat MK, Howell TH, Odle BM, Smith MA. et al.. Effects of NSAIDs on beagle crevicular cyclooxygenase metabolites and periodontal bone loss. J Periodontal Res 1992;27:207-213.

8. Taiyeb Ali TB, Waite IM. The effect of systemic ibuprofen on gingival inflammation in humans. J Clin Periodontol 1993;20:723-728.

9. Jeffcoat MK, Reddy MS, Haigh S, Buchanan W, Doyle MJ, Meredith MP. A comparison of topical ketorolac, systemic flurbiprofen, and placebo for the inhibition of bone loss in adult periodontitis. J Periodontol 1995;66:329-338.

10. D'Aiuto F, Ready D, Parkar M, Tonetti MS. Relative contribution of patient-, tooth-, and site-associated variability on the clinical outcomes of subgingival debridement. I. Probing depths. J Periodontol 2005;76:398-405.
11. Haffajee AD, Thompson M, Torresyap G, Guerrero D, Socransky SS. Efficacy of manual and powered toothbrushes (I). Effect on clinical parameters. J Clin Periodontol 2001;28:937-946.

12. Heasman PA, Seymour RA, Kelly PJ. The effect of systemically-administered flurbiprofen as an adjunct to toothbrushing on the resolution of experimental gingivitis. J Clin Periodontol 1994;21:166-170.

13. Paquette DW, Lawrence HP, McCombs GB, Wilder R, Binder TA, Troullos E. et al.. Pharmacodynamic effects of ketoprofen on crevicular fluid prostanoids in adult periodontitis. J Clin Periodontol 2000;27:558-566.

14. Kuehn BM. FDA panel: keep COX-2 drugs on market: black box for COX-2 labels, caution urged for all NSAIDs. Jama 2005;293:1571-1572.

15. Solomon SD, McMurray JJ, Pfeffer MA, Wittes J, Fowler R, Finn P. et al.. Cardiovascular risk associated with celecoxib in a clinical trial for colorectal adenoma prevention. N Engl J Med 2005;352:1071-1080.

16. Offenbacher S, Odle BM, Braswell LD, Johnson HG, Hall CM, McClure H. et al.. Changes in cyclooxygenase metabolites in experimental periodontitis in Macaca mulatta. J Periodontal Res 1989;24:63-74.

17. Heasman PA, Seymour RA, Boston PF. The effect of a topical non-steroidal antiinflammatory drug on the development of experimental gingivitis in man. J Clin Periodontol 1989;16:353-358.

18. Williams RC, Jeffcoat MK, Howell TH, Rolla A, Stubbs D, Teoh KW. et al.. Altering the progression of human alveolar bone loss with the non-steroidal antiinflammatory drug flurbiprofen. J Periodontol 1989;60:485-490.

19. Holzhausen MC, Rossa Junior E, Marcantonio Junior PO, Nassar DM, Spolidorio LC. Effect of selective cyclooxygenase-2 inhibition on the development of ligatureinduced periodontitis in rats. J Periodontol 2002;73:10301036.

20. Vardar S, Buduneli E, Baylas H, Berdeli AH, Buduneli N, Atilla G. Individual and combined effects of selective cyclooxygenase- 2 inhibitor and omega- 3 fatty acid on endotoxin-induced periodontitis in rats. J Periodontol 2005;76:99106.

Acepted March 13, 2008 